Canadian Journal of Soil Science Revue canadienne de la science du sol

\title{
Exposure to weathering reduces the water repellency of aggregated oil sand material from subsoils of the Athabasca region
}

\begin{tabular}{|r|l|}
\hline Journal: & Canadian Journal of Soil Science \\
\hline Manuscript ID & CJSS-2017-0087.R2 \\
\hline Manuscript Type: & Article \\
\hline Date Submitted by the Author: & 19-Dec-2017 \\
\hline Complete List of Authors: & $\begin{array}{l}\text { Neil, Eric; University of Saskatchewan, Soil Science } \\
\text { Si, B.; University of Saskatchewan, Soil Science }\end{array}$ \\
\hline Keywords: & $\begin{array}{l}\text { water repellency, sub-critical, oil sand, weathering, hydrocarbons (soil), } \\
\text { reclamation (soil, landscape), tarball }\end{array}$ \\
\hline \multicolumn{2}{|l}{} \\
\hline
\end{tabular}

SCHOLARONE

Manuscripts 
Title: Exposure to weathering reduces the water repellency of aggregated oil sand material from subsoils of the Athabasca region

Authors: Eric John Neil ${ }^{1}$, Bing Cheng $\mathrm{Si}^{1, *}$

${ }^{1}$ Department of Soil Science, University of Saskatchewan, Saskatoon, SK, Canada.

*Corresponding author, E-mail address: bing.si@usask.ca 


\begin{abstract}
This study assesses the water repellency (WR) of aggregated oil sand material (AOSM) from the Athabasca region, Canada, and evaluates the onion-skin weathering hypothesis, which postulates that with increasing depth into the soil profile or into individual AOSM samples, the exposure to and extent of weathering of AOSM decreases and petroleum hydrocarbon (PHC) content and WR increase. WR and PHC content were determined for outer and inner portions of AOSM from depths of $15-200 \mathrm{~cm}$. Results show AOSM displays a wide range of WR, in terms of both contact angle (CA) $\left(0^{\circ}\right.$ to $\left.129^{\circ}\right)$ and water drop penetration time (WDPT) $(0$ to $>3600 \mathrm{~s})$. As salvage depth or depth into AOSM increases, PHC content and WR increase, confirming onion-skin weathering. These findings imply the benefit of discreet salvaging into separate layers, as opposed to composite salvaging of shallow and deep soils. Deep materials, which contain relatively high PHC contents, can be salvaged and replaced as deep layers to avoid the excessive drying and expression of WR which may occur in the near-surface. By controlling the location of AOSM within the soil profile, water storage in the rooting zone may be increased, allowing the establishment of relatively productive ecosystems.
\end{abstract}

Keywords: water repellency, sub-critical; oil sand, weathering; hydrocarbons (soil); reclamation (soil, landscape); tarball

Abbreviations: ANOVA, analysis of variance; AOSM, aggregated oil sand material; ASCS, Aurora Soil Capping Study; ATR-FTIR, attenuated total reflectance Fourier transform infrared; Bm, upper subsoil Bm-horizon salvage; B/C, blended B/C-horizons salvage; CA, contact angle; CV, coefficient of variation; PAH, polycyclic aromatic hydrocarbon; PHC, petroleum hydrocarbon; SS, composite subsoil salvage; TOC, total organic carbon; WDPT, water drop penetration time; WR, water repellency/repellent

Short Title: Neil and $\mathrm{Si}-$ Weathering reduces water repellency of oil sand 


\section{INTRODUCTION}

Northern Alberta, Canada is home to the world's largest and richest oil sand reserves, consisting of the Athabasca, Peace River, and Cold Lake deposits, which underlie an area of approximately $142000 \mathrm{~km}^{2}$ [Government of Alberta (GOA) 2016]. Oil sand, or bitumen, deposits are present in over 80 locations worldwide (Meyer et al. 2007), with more than $70 \%$ of these resources located within the Alberta oil sands (Hein 2006). The shallow portions of this region which are accessible through surface mining comprise an area of $4800 \mathrm{~km}^{2}$ near Fort McMurray, AB (GOA 2016). The Alberta government requires oil sands mining companies to reclaim disturbed land and recreate self-sustaining, maintenance-free watersheds and ecosystems with capabilities equivalent to or better than the pre-disturbance conditions (Cumulative Environmental Management Association 2006). The reconstruction of soil profiles is a critical component of any reclamation plan, because the ultimate capability of a reclaimed area is controlled largely by the quality of the reconstructed soil (Oil Sands Vegetation Reclamation Committee 1998). Creation of the soil medium requires selection of an appropriate soil layering prescription, which includes depths, composition, and configuration of reclamation materials (Huang et al. 2011). In order to effectively prepare reclamation prescriptions, an understanding of each of the available materials is essential.

A soil survey performed in the Athabasca oil sands region shows that considerable quantities of petroleum hydrocarbon $(\mathrm{PHC})$ affected soils are present in the form of aggregates and layers within the top three meters of these dominantly coarse-grained Brunisolic soils (Leskiw et al. 2006). One of the most common surficial hydrocarbon deposits of the region is aggregated oil sand material (AOSM), previously referred to as "tarballs" (Fig. 1). These aggregates are PHC-impregnated materials with a similar texture to that of the surrounding soil, and are typically millimeters to tens of centimeters in diameter (Fleming 2012). The materials available for reclamation in this region may originate from the near surface horizons of the profile and; therefore, have the potential to contain AOSM, which may or may not inhibit the 
plant roots, soil organisms, and soil processes required for the recovery and maintenance of a stable ecosystem (Visser 2008). Several studies have shown that PHCs, such as those contained within oil sand bitumen, are often associated with WR (Walker et al. 1976; Roy and McGill 2000; Quyum et al. 2002; Buczko et al. 2006; Brassington et al. 2007; Adams et al. 2016), and it has been hypothesized that the weathering of PHCs will typically shift their chemical composition toward relatively recalcitrant products with greater hydrophobicity (Walker et al. 1976; Brassington et al. 2007). Polycyclic aromatic hydrocarbons (PAH) are a common class of PHC present in oil sand bitumen, and have the potential to produce hydrophobicity and soil water repellency (Cerniglia 1992; Zhou and Zhu 2005). Typically, low molecular weight PAHs such as naphthalene and phenanthrene are rapidly degraded in sediments and soils, whereas high molecular weight PAHs such as benz[a]anthracene, chrysene, and benzo[a]pyrene, which are relatively insoluble and highly resistant to degradation, may persist indefinitely (Cerniglia 1992). This is largely due to the decreasing enzymatic capability of soil microorganisms to degrade PHCs of increasing complexity (Walker et al. 1976). Although microbial degradation of heavy PAHs may occur, there are a limited number of species of microorganisms that are capable of complete mineralization (Cerniglia 1992; Zhou and Zhu 2005). Additionally, as molecular size increases, solubility and mobility decrease, which further promotes the depletion of light PHCs and enrichment of heavy PHCs within the weathered oil sand (Mossop 1980; Eastcott et al. 1988; Fleming 2012). Generally, low-molecular-weight PHCs are preferentially degraded, volatilized, and leached from bitumen, resulting in the accumulation of heavier, more complex PHCs over time (Mossop 1980; Brunner et al. 1987; Cerniglia 1992).

Previous investigations have confirmed that typical AOSM from the Athabasca oil sands region is composed primarily of relatively heavy hydrocarbons, such as those from the F3 and F4 fractions of the classification system provided by the Canadian Council of Ministers of the Environment (CCME) (2008) in their Canada-Wide Standards for Petroleum Hydrocarbons (PHC) in Soil (Fleming 2012). Volatile hydrocarbons, including benzene, toluene, ethylene, 
xylene and other low molecular weight hydrocarbons such as those from the CCME (2008) F1 fractions, are typically undetectable; whereas, F2 hydrocarbons are slightly more abundant with concentrations above detectable limits (Fleming 2012). Exceptions have been found in AOSM with "rich" cores, which can contain total PHC contents that are orders of magnitude greater than typical AOSM, including elevated levels of the relatively light F1 and F2 hydrocarbons (Fleming 2012). Under normal field conditions, the F1 and F2 fractions are relatively soluble and easily transported in water, whereas the heavier F3 and F4 fractions are nearly insoluble (Fleming 2012). The ability to readily dissolve in water indicates that the F1 and F2 PHCs are hydrophilic, and the relative insolubility of the F3 and F4 fractions suggests hydrophobicity (Page et al. 2000; Reid et al. 2000). Typically, the PHCs remaining in AOSM are relatively heavy in composition, so differences in WR will likely be due to differences in the total PHC content as opposed to differences in PHC composition. Roy et al. (2003) showed that total PHC content was positively correlated with soil water repellency in 12 petroleum-contaminated sites in central Alberta.

The Alberta oil sands are somewhat unique in composition: the bitumen is not in direct contact with the mineral particle portions of the oil sand; upon formation there is a thin lens of connate water surrounding the mineral particles, separating the mineral particles from the bitumen contained within the centers of the pores (Mossop 1980; Takamura 1982). This physical arrangement has two important implications for WR: mineral particles are originally surrounded by water and are; therefore, considered hydrophilic (Mossop 1980; Takamura 1982; Gu 2006); and water that is introduced to the pore structure of the oil sand is in direct contact with the exposed interstitial bitumen rather than the sheltered mineral portions, suggesting that the water repellent nature of the oil sand will be primarily, if not exclusively, controlled by the WR characteristics of the bitumen within. Depending on the location and site specific characteristics, WR may be enhanced or diminished, affecting the wettability, soil water retention, and consequently the ecosystem (Diehl 2013). Therefore, when attempting to reclaim 
a hydrocarbon-affected area such as the Alberta oil sands, it is important to understand the potential soil water repellency of the available reclamation materials. Aggregated oil sand material is one such potentially WR material, which is present in many of the soils in this region, and is composed primarily of sand and PHCs, both of which are prone to WR.

Since the PHCs remaining in the AOSM are thought to cause WR, the water repellent behaviour of the material should be directly related to the extent of weathering, and consequently the amount of PHC remaining. As biodegradation occurs and hydrophobic molecules are broken down, water repellency is reduced (Bisdom et al. 1993; Dekker and Ritsema 1994). The limited biodegradation of the heavy hydrocarbon fractions (F3 and F4) which are present in oil sand, is most likely a biotransformational process which can render larger, more complex PHCs into several smaller "daughter" PHC compounds (Fleming 2012). These daughter compounds are more easily dissolved in soil solution and leached from the AOSM than the parent compounds. It is also known that the presence of oxygen typically increases the biodegradation rate of crude oil constituents (Cerniglia 1992; Frontera-Suau 2000; Gu 2006; Zhao and Machel 2011). Based on the above it stands to reason that the outer portions of AOSM, which are more exposed to weathering and degradation agents, should contain fewer PHCs and exhibit less WR than the more protected inner portions. The AOSM with rich cores that were observed by Fleming (2012) also suggest this. Similarly, near-surface AOSM deposits should be more exposed to weathering, contain fewer PHCs, and exhibit less WR than deeper deposits.

We hypothesize that AOSM undergoes "onion-skin weathering", where the amount of weathering or degradation decreases and consequently the PHC content and WR increase, with increasing depth from the soil surface as well as with increasing depth into individual AOSM samples. To test these hypotheses, the WR of AOSM from various salvage depths and apparent stages of weathering were determined. The objective of this study is to evaluate the 
onion-skin weathering hypothesis of AOSM, to better understand the dynamics of oil sand weathering and its effects on soil hydraulic properties such as WR.

\section{MATERIALS AND METHODS}

\section{Study Site and Reclamation Materials}

The study area is located in the Central Mixedwood Natural Subregion within the Boreal Forest Natural Region of Alberta (Natural Regions Committee 2006). The area may be further distinguished into smaller components called ecosite phases, based on moisture and nutrient regimes, as outlined in Beckingham and Archibald (1996). The study region has been known to support portions of 'a', 'b', and 'd' ecosite phases (Zettl et al. 2011), characterized by subxeric, submesic, and mesic moisture regimes respectively, and by poor ('a' ecosites) and medium ('b' and 'd' ecosites) nutrient regimes (Beckingham and Archibald 1996). Parent materials in the area are composed primarily of glaciofluvial sands and gravels, giving rise to coarse-textured Brunisolic soils (Leskiw et al. 2006). These soils most commonly support the 'a1' ecosite phase, which is characterized by a subxeric moisture regime and poor nutrient regime, with jack pine (Pinus banksiana Lamb) and lichen (Cladina spp. and Cladonia gracilis) as the dominant tree and understory species (Beckingham and Archibald 1996). Prior to surface mining, the forest vegetation, soils, and lean oil sand overburden are removed to depths of up to $100 \mathrm{~m}$ in order to reach the desired oil sand reserves (Johnson and Miyanishi 2008). The excavated overburden and soil materials are then stored in stockpiles. These materials, and potentially additional peat and soils collected from neighboring undisturbed areas, are available for later use in reclamation (Johnson and Miyanishi 2008).

In order to test the efficacy of utilizing various soil reclamation prescriptions, as well as to explore the potential impacts to ecological receptors (i.e. vegetation, microbial communities, surface and ground waters, etc.) that may occur in hydrocarbon-affected reclamation soils, a long-term instrumented watershed research site called the Aurora Soil Capping Study (ASCS) 
was established in 2012 at Syncrude Canada Ltd.'s Aurora North Mine, north of Fort McMurray, AB. The ASCS site contains 36 one-hectare plots, consisting of 12 reclamation treatments repeated in triplicate. The treatments are composed of various combinations of hydrocarbonaffected soil materials that were collected from the area prior to surface mining. Soils and subsoils containing AOSM were collected from the following materials of the ASCS:

- Upper Subsoil Bm horizon salvage $(15-50 \mathrm{~cm})$ : Surface soil was removed (LFH layer, A horizon, and a portion of the top of the B horizon which totals approximately $15-20 \mathrm{~cm}$ ), then the remaining $\mathrm{Bm}$ horizon was salvaged to a depth of $50 \mathrm{~cm}$.

- Blended B/C horizons salvage $(50-100 \mathrm{~cm})$ : Surface soil and upper subsoil Bm horizon were removed $(0-50 \mathrm{~cm})$, then the remaining $B$ horizon and a portion of the $C$ horizon were salvaged to a depth of $100 \mathrm{~cm}$.

- Composite Subsoil salvage $(15-200 \mathrm{~cm})$ : Surface soil was removed (LFH layer, A horizon, and a portion of the top of the B horizon which totals approximately $15-20 \mathrm{~cm}$ ), then the remaining $\mathrm{Bm}$ horizon and a portion of the $\mathrm{C}$ horizon were salvaged to a depth of $200 \mathrm{~cm}$.

The three soil salvage types will be referred to as $\mathrm{Bm}, \mathrm{B} / \mathrm{C}$, and $\mathrm{SS}$ respectively. The soils were originally salvaged by Syncrude Canada Ltd. in various depth ranges and intervals, in order to compare the effects of discreet and composite salvaging techniques on the success of reclaimed soil profiles. Discreet salvaging involves the removal (prior to mining) and replacement (during reclamation) of soil layers in distinct soil horizons, such as those of the Bm and $\mathrm{B} / \mathrm{C}$ salvages. Composite salvaging is the removal and replacement of relatively large sections of the soil profile, with little concern for material composition, as in the case of the SS salvage. It was posited that, due to the relatively uniform composition of the soils throughout the depth of the soil profiles in the region, discreet salvaging may be unnecessary. If so, composite salvaging would provide an alternative technique which promotes reclamation success, but that is superior in terms of economic and environmental efficiency. Composite techniques minimize 
the use of heavy machinery, consequently conserving resources, and mitigating the ecological footprint of mining and reclamation activities by reducing green house gas emissions.

In-tact AOSM samples, ranging from centimeters to decimeters in diameter, were chosen randomly from each of the available salvage materials and their surfaces lightly brushed to remove the excess sand matrix. Aside from periods of active testing, which were performed at $20{ }^{\circ} \mathrm{C}$ and $30 \%$ relative humidity, the AOSM was stored at $4{ }^{\circ} \mathrm{C}$ to minimize microbial degradation. Prior to testing, the AOSM was air dried at $20{ }^{\circ} \mathrm{C}$ and $30 \%$ relative humidity, for a period of several days to weeks, until reaching a constant mass.

In addition to their salvage type, the majority of the AOSM samples were categorized into one of three relative weathering stages (low, medium, or high), based on physical stability, visual appearance, and odour (Table 1). To assess the physical stability, the relative force required to cause the sample to physically fragment, or break, was determined. Firstly, the sample was brushed with a soft-bristled paint brush, and if fragmentation occurred then the sample was considered highly weathered in terms of physical stability. Secondly, if the sample did not fragment with the use of a paint brush, but could be broken by hand, it was considered to be at a medium stage of weathering. Lastly, if fragmentation of the sample required the use of a steel hammer and chisel, it was classified as low-weathered. The visual signs of weathering were based on the colour of the sample, as well as whether it contained a light-coloured precipitate on portions of it's surface, where the presence of a precipitate indicated a higher stage of weathering. The level of petroleum odour was determined simply by smelling the sample while it was approximately $5 \mathrm{~cm}$ from the assessor's nose. A clear and strong odour of petroleum indicated a low stage of weathering, a faint odour indicated a medium stage, and the absence of a petroleum odour indicated a high stage of weathering. Generally, AOSM would receive the same classification (low, medium, or high) using each of the three criteria (visual appearance, physical stability, and odour). For samples where one of the three weathering criteria came to a different conclusion, the weathering stage was based on the majority (i.e. 
weathering stage indicated by the two criteria with matching conclusions). For samples where all three weathering criteria suggested a different weathering stage, the sample was classified as medium weathered.

A Horiba LA-950 particle size analyzer was used to determine the particle size distributions for the AOSM and soil matrix (Horiba Scientific, Edison, NJ, USA). Particle sizes were categorized into soil separates using the classification systems of the Canadian Soil Survey Committee and United States Department of Agriculture, which define soil separates as sand (< $2000 \mu \mathrm{m}$ to $50 \mu \mathrm{m})$, silt $(<50 \mu \mathrm{m}$ to $2 \mu \mathrm{m})$, and clay $(<2 \mu \mathrm{m})$ (Dane and Topp 2002). The soil textures were determined using the Canadian System of Soil Classification (Soil Classification Working Group 1998). The mass-based total organic carbon (TOC) contents of AOSM and soil matrix from the three salvage types were determined using a LECO C-632 dry combustion carbonator (LECO Corp., St. Joseph, MI, USA) (Wang and Anderson 1998). Because these soil materials contain limited soil organic matter, it can be assumed that the measured TOC is primarily of petroleum origin.

The most common type of hydrophobic substance causing WR in sands are amphiphilic molecules, polar organic molecules containing both hydrophilic and hydrophobic portions (Doerr et al. 2000; Diehl 2013). For such a case, the affected material may act in a hydrophobic or hydrophilic manner, depending on the antecedent water content as well as $\mathrm{pH}$ and temperature (Doerr et al. 2000; Diehl 2013). Furthermore, soils affected by WR may change their behaviour from hydrophobic to hydrophilic during wetting, and vice versa during drying (Dekker and Ritsema 1994; Doerr et al. 2000). This is certainly the case in the Athabasca oil sands region, where studies by Hunter (2011) and Chau et al. (2014) have illustrated the dependence of wetting duration on the WR of both natural (undisturbed) and reclamation (disturbed) soil materials.

\section{Measurement of Water Repellency}


Due to the temporally transient nature of WR in the study region, both the degree and persistence of WR of the AOSM were determined. The degree of WR of air-dry soil materials can be used to determine the maximum or potential WR that may be experienced after prolonged drought periods (Müller and Deurer 2011). The sessile drop CA between a water droplet and the material surface represents the degree of WR and provides a measurement at a fixed point in time (Dekker and Ritsema 1994; Diehl 2013). The WDPT represents the persistence of WR and provides measurements through time (Dekker and Ritsema 1994; Müller and Deurer 2011). This indicates whether the potential for WR, as indicated by the CA, will have a substantial effect on water absorption and conductivity of AOSM.

The degree of WR of the AOSM was determined via sessile drop CA analysis, using a PGX pocket goniometer (FIBRO Systems AB, Hägersten, Sweden). The PG-X delivers a controlled volume of water to the surface of the material. In the current study, this procedure utilized $3 \mu \mathrm{L}$ deionized, de-aired water droplets. Once a water droplet was applied and its equilibrium position reached, the on-board camera was used to take photographs of the water droplet on the surface of the material. The photographs were used in conjunction with ImageJ software (Rasband 1997-2012) and the Low Bond Axisymmetric Drop Shape Analysis method outlined by Stalder et al. (2010), to determine the water contact angles. Several AOSM samples from each of the available soil salvage types were tested $(B m=27 ; B / C=21 ; S S=11)$, for a total of 59 samples. Each sample was tested three to six times on relatively flat portions of it's outer surface, with measurement locations spaced approximately equidistantly across the surface of the sample. The mean CA for each AOSM sample was then obtained to account for variability within samples. There are three general scenarios that can arise when examining CA: spontaneous wetting or infiltration (hydrophilic or wettable) where CA = zero; partial wetting (subcritical WR) where $0^{\circ}<\mathrm{CA} \leq 90^{\circ}$; and non-wetting (critical WR or hydrophobic) where CA $>90^{\circ}$ (Müller and Deurer 2011). When the CA is above $90^{\circ}$ water should theoretically never infiltrate, but when it is $90^{\circ}$ or less, capillary forces will draw water into the sample (Dekker and Ritsema 1994). This 
information provides insight into the stability of water repellency and is another indication of its persistence (Dekker and Ritsema 1994). Therefore, the times for the CAs of the AOSM to become $\leq 90^{\circ}$ were also determined for samples from each salvage type $(B m=23 ; B / C=21$; SS $=11$ ), which totalled 55 samples. It is important to note; however, that water will not always infiltrate when CAs are less than $90^{\circ}$. The geometry or shape of soil particles can affect the interactions between solid surfaces and liquids, and prevent infiltration into seemingly subcritically-WR surfaces $\left(C A<90^{\circ}\right)($ Shirtcliffe et al., 2010). For example, a curved or fibre-like structure can suspend a liquid, or prevent infiltration, when it's sessile CA is between $0^{\circ}$ and $90^{\circ}$ (Shirtcliffe et al., 2010). Additionally, particle size can have an effect on the infiltration of water into subcritically-WR soils, such that soils with liquid CAs $<90^{\circ}$ may exhibit incomplete wetting or non-wetting behaviours (Hamlett et al., 2011). Hamlett et al. (2011) found that the smaller the diameter of soil particles, the smaller the liquid contact angles could be while still preventing infiltration. In other words, the critical contact angle, or the largest contact angle at which infiltration commences, decreases as particle size decreases (Hamlett et al., 2011). Therefore, although a CA of $90^{\circ}$ is being used as an indication for the likely threshold between partially wettable and non-wettable surfaces in this study, there may be exceptions to this rule. Due to this uncertainty, the times for the CAs to become less than $90^{\circ}$ should be considered as merely a possible indication of WR rather than an absolute measure, and the initial sessile drop CAs and WDPTs should be treated as the primary representations of WR in this study.

The persistence of WR was also determined using the CA goniometer. As the $3 \mu \mathrm{L}$ water droplets infiltrated the AOSM surface, additional CA images were taken at various times throughout infiltration. These changes in CA over time, from maximum CA to zero, represent the WDPT. In addition to the goniometer measurements, persistence was measured on several samples using another form of the WDPT test. Water droplets (40 $\mu \mathrm{L})$ were introduced to the AOSM using an autopipette, and the time for complete infiltration was recorded. The WPDT 
measurements were performed on samples from each of the soil salvage types $(\mathrm{Bm}=35 ; \mathrm{B} / \mathrm{C}=$ 24; SS $=13$ ), providing a total of 72 samples. As with the CA testing, the WDPT measurements were performed on reasonably flat locations and spaced roughly equally across the surface of the sample. Each sample was measured approximately 10 times and the mean WDPTs of each sample determined, in order to account for variability within samples. The WDPT classification scheme of Bisdom et al. (1993) was then used to categorize the AOSM samples into repellency classes.

In order to test the onion-skin weathering hypothesis, the degree and persistence of WR were measured on the surfaces of AOSM samples from multiple salvage depths $(B m, B / C, S S$ salvages). To further test this hypothesis, the WR of the inner portions of several samples were determined in addition to the surface measurements. To access the inner portions of these samples, a steel dental pick and spatula were used to remove material to a desired depth. Material was removed in $10 \mathrm{~mm}$ diameter holes in depth increments of 3 to $10 \mathrm{~mm}$. The sample was then air dried before performing the WDPT measurements. This was completed at one to three depths per test location to a total depth of 3 to $24 \mathrm{~mm}$, depending on individual AOSM sample thickness.

\section{Infrared Measurement of AOSM Surface Precipitate}

A select number of AOSM samples contained a light-coloured (white) precipitate on their outer surface, which is consistent with previous studies of oil sand material. It has been observed that salt precipitates often form on and around the outer surfaces of AOSM (Visser 2008). The high concentrations of sulphur (800 to $1200 \mathrm{mg} \mathrm{kg}^{-1}$ ) within AOSM would suggest the precipitate is likely a sulphate salt, possibly calcium sulphate, that forms from sulphur entering soil solution and traveling to the surface of the AOSM where it precipitates with calcium (Visser 2008). The high suphur content of AOSM and the existence of precipitates on many of the aggregates suggests the presence of a sulphate compound. To explore this possibility, attenuated total reflectance Fourier transform infrared (ATR-FTIR) spectroscopy was performed 
to test for the presence of sulphate within the outer and inner portions of the four AOSM samples that were WR tested at multiple depths. The ATR-FTIR experiments were performed using a Bruker Optics Equinox 55 FTIR spectrometer (Bruker Optics, Milton, ON, Canada), which was equipped with an $\mathrm{N}_{2}$-cooled mercury cadmium telluride detector and a single bounce ZnSe diamond coated crystal ATR accessory. The background spectrum of the crystal was collected and later subtracted from the sample spectra prior to data analysis. Material was collected from the outer and inner portions of each of the four AOSM samples, ground into a fine powder, and individually pressed onto the diamond crystal surface for measurement. The ex-situ FTIR spectra of the various samples were then determined over a wavenumber range of 4000 to $700 \mathrm{~cm}^{-1}$. Each of the obtained spectra are the result of 512 co-added scans taken at a resolution of $4 \mathrm{~cm}^{-1}$.

\section{Statistical Analysis}

Pearson's r was used to explore potential linear correlations among soil texture, TOC, CA, WDPT, and measurement depth. One-way analysis of variance (ANOVA) were performed to explore differences in the tested variables, where differences in means were considered significant at $\mathrm{P}<0.05$.

\section{RESULTS \& DISCUSSION}

\section{Physical Properties of Reclamation Materials}

The weathering classification of AOSM showed that the low weathering class primarily included AOSM from the deep salvage $(B / C)$; the medium class was composed of all salvage types (Bm, B/C, and SS); and the highly weathered class included materials from the shallowest depths (Bm and SS) (Fig. 2, Table 2).

Soil matrix and AOSM from each of the salvage types are sand textured soils, with the exception of two AOSM samples which are classified as loamy sand. Neither the AOSM $(0.0 \%)$ nor the soil matrix $(0.4 \%)$ contain substantial amounts of clay; however, due to the absence of 
clay in the AOSM, ANOVA showed that AOSM have a significantly lower clay content than the surrounding soils. ANOVA also revealed that outer and inner potions of AOSM are not significantly different in texture (soil separates).

The mean TOC contents with standard deviations, of the soil matrix, outer AOSM, and inner AOSM are presented in Table 2. ANOVA revealed the TOC contents of the outer and inner portions of AOSM are significantly different, where the inner material $(9.6 \%)$ has a greater mean TOC content than the outer $(7.5 \%)$. The low weathered AOSM contained significantly greater TOC contents (13.0\%) than the high (6.5\%) and medium (6.4\%) classes (Fig. 3). Furthermore, there is a positive correlation between TOC content and depth into AOSM samples (Fig. 3).

\section{Degree and Persistence of Water Repellency}

The maximum CAs of the air-dry AOSM samples measured anywhere from $0^{\circ}$ (hydrophilic) to $129^{\circ}$ (hydrophobic), where $\geq 75 \%$ showed some level of water repellency $\left(C A>0^{\circ}\right)$ and the remainder were wettable $\left(C A=0^{\circ}\right)\left(\right.$ Fig. 4). The mean $(\mu)$ maximum CA for all samples was $47^{\circ}$ with a coefficient of variation $(\mathrm{CV})$ of $96 \%$. The shallow salvage $(\mathrm{Bm})$ primarily showed wettability or subritical WR $\left(\mu=28^{\circ}\right.$; CV $\left.=115 \%\right)$, while the SS salvage was predominantly hydrophobic $\left(\mu=96^{\circ} ; \mathrm{CV}=36 \%\right.$ ). The $\mathrm{B} / \mathrm{C}$ salvage showed a range of WR behaviour, which included hydrophilic, subcritically WR, and hydrophobic materials ( $\mu=47^{\circ} ; \mathrm{CV}=100 \%$ ). Similarly, the water repellency of salvage materials also depended on the degree of weathering: AOSM of medium $\left(\mu=53^{\circ} ; \mathrm{CV}=94 \%\right)$ and high $\left(\mu=49^{\circ} ; \mathrm{CV}=101 \%\right)$ degree of weathering varied from wettable to hydrophobic, while all materials of a low $\left(\mu=105^{\circ}\right.$; CV $\left.=17 \%\right)$ degree of weathering were hydrophobic. When observing the contact angles through time, more than $70 \%$ of the droplets had $\mathrm{CA} \leq 90^{\circ}$ within $5 \mathrm{~s}$ of contact, and the remainder was divided approximately equally between droplets with $\mathrm{CA} \leq 90^{\circ}$ within $60 \mathrm{~s}$, and those greater than $60 \mathrm{~s}$ (Fig. 5).

The WDPTs from both the goniometer and autopipette testing were combined and presented in Figure 6. The mean WDPT for all samples was 824 s with a CV of $221 \%$. 
Approximately $1 / 3$ of the samples are classified as hydrophilic with WDPTs $\leq 5 \mathrm{~s}$, less than $1 / 3$ are slightly WR with WDPTs from 5 to $60 \mathrm{~s}$, and more than $1 / 3$ are strongly to extremely WR with WDPT $\geq 60 \mathrm{~s}$. Similar to the CA results, the SS salvage predominantly showed extremely water repellent WDPTs $(\mu=3250 \mathrm{~s} ; \mathrm{CV}=90 \%$ ), the Bm was mainly wettable to slightly water repellent $(\mu=270 \mathrm{~s} ; \mathrm{CV}=381 \%)$, and the B/C showed a range of WDPTs $(\mu=331 \mathrm{~s} ; \mathrm{CV}=$ $156 \%$ ). Furthermore, the degree of weathering also affected soil water repellency, where AOSM with a low degree of weathering $(\mu=3775 \mathrm{~s} ; \mathrm{CV}=95 \%)$ showed strong to extreme $\mathrm{WR}$, a high degree of weathering ( $\mu=903 \mathrm{~s} ; \mathrm{CV}=227 \%$ ) resulted in mainly wettable to strongly WR materials, and the medium weathered ( $\mu=659 \mathrm{~s} ; \mathrm{CV}=231 \%$ ) AOSM showed a range of WR from wettable to severely WR. The degree and persistence of WR of the AOSM are related, where there is a linear correlation $\left(r^{2}=0.81\right)$ between CA and the natural logarithm of WDPT. There also appears to be a correlation between WR and salvage depth (Fig. 4; Fig. 6), where greater salvage depth generally results in a greater degree (CA) and persistence (WDPT) of $\mathrm{WR}(\mathrm{B} / \mathrm{C}$ and $\mathrm{SS}>\mathrm{Bm})$.

The WDPTs indicate that the majority of the AOSM will allow infiltration within the first minute of exposure, another portion within $10 \mathrm{~min}$, and some that are severely or extremely WR with WDPTs greater than $10 \mathrm{~min}$. Hunter (2011) investigated the WR of soils from several hydrocarbon-affected reclamation sites and natural 'a' ecosites in the Athabasca region. The sites showed similar WR, with WDPTs ranging from 0 to $122 \mathrm{~s}$ and CAs from $0^{\circ}$ to $>110^{\circ}$, where the variability was high in both land types with coefficients of variation often exceeding $200 \%$. Although the magnitude of WR in the soils tested by Hunter (2011) was generally lower than the AOSM in the current study, a high level of variability was present in both materials, indicating that the spatial variability of WR in the AOSM from the current study is comparable to that of other natural soil materials in the region. 
The WR of the tested AOSM showed a strong dependence on wetting duration. Although repellency is present to some extent in much of the AOSM, according to the CA analysis, over half of the material will wet either immediately (hydrophilic) or eventually if given adequate time (subcritically WR) (Fig. 4). The remainder are hydrophobic and theoretically may never have the capability of wetting and allowing infiltration in their current condition. The results of Hunter (2011) and Chau et al. (2014) confirm the dependence of wetting duration on the WR of natural and reclaimed hydrocarbon-affected soils, where CA and WDPT were negatively correlated with antecedent soil water content. In addition to the CA and WDPT values themselves, the time it takes for a soil CA to change from $>90^{\circ}$ to $\leq 90^{\circ}$ also has important implications. In the current study, very few samples $(<20 \%)$ had a $C A>90^{\circ}$ for longer than one minute, suggesting that the vast majority (> $80 \%$ ) of the AOSM began to allow at least some infiltration within one minute of contact with water, and are thus considered to be either hydrophilic (WDPT $=0 \mathrm{~s}$ ) or subcritically WR (WDPT > $0 \mathrm{~s}$ ). This is also consistent with Hunter (2011) who found that the majority of hydrocarbon-affected soils, in both natural and reclaimed sites, are wettable or subcritically WR according to CA analysis.

These results are also consistent with water repellency theory. Some material surfaces are seemingly water repellent $\left(\mathrm{CA}>90^{\circ}\right)$ when first introduced to water, but with time and exposure to water, their amphiphilic molecules reorient themselves to a hydrophilic position which enables infiltration (Dekker and Ritsema 1994; Doerr et al. 2000). This is typically what is observed in the highly weathered or shallow AOSM. In other cases; however, surfaces can be so WR (typically when $\mathrm{CA}>90^{\circ}$ ) that the molecules are unable to reorient themselves within a reasonable or observable time frame, if ever, and are thus considered hydrophobic (Dekker and Ritsema 1994; Doerr et al. 2000), which is what is observed in the low weathered or deep salvage AOSM. This is also consistent with the observed linear correlation $\left(r^{2}=0.81\right)$ between CA and WDPT of AOSM in the current study. However, it is important to note that CA and WDPT are not always related. Bachmann et al. (2007) found a significant relationship between 
the CA and WDPT when the CA was $>90^{\circ}$; whereas, for smaller CAs $\left(\leq 90^{\circ}\right)$ the WDPT was found to be $<5 \mathrm{~s}$, and it was concluded that the measurement of WDPT is insensitive to differences in wettability throughout the entire range from wettable to hydrophobic. This phenomena is exhibited in a study performed by Chau et al. (2014) on soils from undisturbed 'a' ecosites and reclaimed sites in the Athabasca region, which showed that CA and WDPT can be, but are not always, correlated.

The wettable or subcritical nature of the WR in AOSM has been verified by the results of an accompanying tension-controlled infiltration experiment performed on the same AOSM samples used in the current study. The majority of the AOSM allowed infiltration to occur under negative pore water pressures ranging from -20 to $-0.1 \mathrm{~cm}$ (Neil and $\mathrm{Si}$, manuscript in preparation), indicating subcritical WR with CAs $\leq 90^{\circ}$ (Bauters et al. 2000). However, the infiltration of 95\% ethanol was also determined, under pressure conditions equivalent to those used for water (i.e. the height of ethanol in the infiltration column was adjusted based on the difference in densities of water and ethanol) (Neil and $\mathrm{Si}$, manuscript in preparation). The results showed that ethanol infiltration was significantly $(P<0.05)$ higher than that of water, indicating that WR is indeed producing some appreciable effect on the absorption and conductivity of water in the AOSM (Neil and $\mathrm{Si}$, manuscript in preparation).

\section{Water Repellency with Depth}

There were clear differences in WR between outer (surface; depth $=0 \mathrm{~cm}$ ) and inner (below surface; depth $>0 \mathrm{~cm}$ ) portions of the AOSM. The inner material showed a greater degree (CA) and persistence (WDPT) of WR than the outer material, with few exceptions. There is a linear correlation between measurement depth and WDPT, with an $r^{2}=0.61$ (Fig. 7). The AOSM sample, of medium to high weathering, from the $B / C$ horizons salvage $(B / C-1)$ had a poor depth-WDPT relationship with an $\mathrm{r}^{2}=0.03$; however, the remaining samples (B/C-2, SS-1, and $B m-1)$ showed strong to moderate correlations with $r^{2}$ values of $0.93,0.69$, and 0.62 
respectively. A clear difference can be seen between the AOSM of different weathering classes (Fig. 7). The least weathered AOSM has the greatest WR and the best relationship between depth and WDPT $\left(r^{2}=0.93\right)$; the medium AOSM have intermediate WR and reasonable depthWDPT relationships $\left(r^{2}=0.69\right.$ and 0.62$)$; and the highly weathered AOSM is generally the least WR and has the weakest relationship with depth $\left(r^{2}=0.03\right)$.

The CA and WDPT increased with salvage depth (Fig. 4; Fig. 6) and; therefore, there is a positive correlation between WR and salvage depth. This is because shallow AOSM deposits, which are nearer to the soil surface and more exposed to weathering agents prior to salvage, should have a smaller amount of hydrophobic PHC material than AOSM from deeper deposits. As shown in Figure 2 and Table 2, the Bm horizon salvage which contains materials from the 15 to $50 \mathrm{~cm}$ depth, had less TOC than the $\mathrm{B} / \mathrm{C}$ horizons salvage (50 to $100 \mathrm{~cm}$ ). The SS salvage contains materials between 15 to $200 \mathrm{~cm}$, where one would expect a greater abundance of lowweathered AOSM; however, the TOC results suggest it contains mainly highly weathered AOSM. This may indicate that AOSM from the SS salvage used in this study originated primarily from shallow depths. In other words, the SS salvage is composed mainly of AOSM from the Bm horizon $(15$ to $50 \mathrm{~cm}$ ) and very few from the 50 to $200 \mathrm{~cm}$ range. Therefore, there is clearly a dependence of both WR and TOC on salvage depth.

There is also a negative correlation between WR and the AOSM stage of weathering (Fig. 4; Fig. 6). Samples from the lowest stage of weathering were more likely to have the greatest WR and include AOSM from the deep salvage $(B / C)$; medium weathered AOSM showed a range of $W R$ and included all salvages $(\mathrm{Bm}, \mathrm{B} / \mathrm{C}$, and $\mathrm{SS})$; and the highly weathered $\mathrm{AOSM}$ are the least WR and found in the shallowest material (Bm and SS) (Fig. 2; Fig. 4; Fig. 6). However, due to the unknown pre-disturbance depths of the individual AOSM samples, further analysis of this relationship is not feasible. A similar result was reported by Zhao and Machel (2011) for a site in the Athabasca region, where the biodegradation of oil sand bitumen was found to decrease with depth. 


\section{Onion-Skin Weathering}

The relationships among WR, weathering, salvage depth, and TOC confirm the onion-skin weathering hypothesis. As salvage depth increases, exposure to weathering and biodegradation decreases, and consequently TOC and WR increase. Additionally, WDPT and TOC are correlated with depth into AOSM samples (Fig. 3; Fig. 7). Aside from the WDPT results of sample $\mathrm{B} / \mathrm{C}-1$, these results also confirm the onion-skin weathering hypothesis, where TOC and WR increase with depth into the AOSM. The onion skin weathering of AOSM is similar to the spheroidal weathering of rock. Spheroidal weathering results in concentric layers of intact, weathered rock to form sequentially around a central corestone, through fracturing due to mineralogical, chemical, and mechanical processes (Hirata et al. 2016). Typical weathering agents include reactants such as oxygen and water, which advance toward the inside of the corestone (Hirata et al. 2016). In a study focused on the weathering of charnockitic bedrock, Behrens et al. (2015) found that primary minerals are initially removed, leaving behind secondary minerals and crystalline oxides as well as increased porosity. As weathering proceeds, the increase in porosity further increases the ability of reactive substances to penetrate the inner portions of the rock, resulting in enhanced weathering (Behrens et al. 2015). It appears that the removal of PHCs from AOSM may be a similar process: as weathering proceeds, PHCs are removed from the outer portions of the AOSM, increasing porosity and allowing further penetration of weathering agents. This suggests that the spheroidal weathering and removal of PHCs in AOSM are responsible for the decrease in TOC and increase in WR, with depth into the soil profile as well as with depth into individual AOSM samples.

\section{AOSM Surface Precipitate}

The outer surface of sample B/C-1 differed from the other three WDPT-depth samples, based on visual assessment. It contained extensive cracking, a lighter colour including the presence of a white precipitate on some portions, and a seemingly lower PHC content as was 
suggested by the colour and by the absence of a strong petroleum odour. These characteristics are indications of strong weathering. However, the surface of this AOSM exhibits substantial WR, contradicting the strong inverse relationships between WR and the degree of weathering and depth into the AOSM. It is possible that the WDPT-depth relationship, which is considerably stronger for other samples, has been modified in sample B/C-1 by the presence of a sulphate compound. The ATR-FTIR results from the outer portions of sample B/C-1 showed a peak absorbance at a wave number of approximately $1100 \mathrm{~cm}^{-1}$, which indicates the presence of sulphate (Peak et al. 1999). The outer and inner positions of the other three AOSM samples showed no peak absorbance at $1100 \mathrm{~cm}^{-1}$, with the exception of a portion of the outer surface of sample Bm-1. The outer surface of $\mathrm{Bm}-1$ also contained portions that were similar in appearance to that of B/C-1. However, the previous WDPT-depth measurements of this sample were not performed on the surface(s) which contained the sulphate precipitate, which may explain why Bm-1 did not show a poor WDPT-depth relationship like that of sample B/C-1. Furthermore, additional WR tests confirmed that the portions of Bm-1 which contained sulphate, had a greater mean CA and WDPT on its outer portions $\left(83^{\circ}, 87 \mathrm{~s}\right)$ than inner $\left(77^{\circ}, 15 \mathrm{~s}\right)$.

It is possible that sulfate combined with organic substances to form a surfactant (Jafvert and Heath 1991; Zhou and Zhu 2005). Surfactants have the ability to increase the solubility of hydrophobic organic compounds and decrease water repellency, and are a typical means of remediation for various hydrophobic environmental contaminants including PAHs (Jafvert and Heath 1991; Zhou and Zhu 2005). However, depending on the type of surfactant, precipitation and sorption of the surfactant may occur on soil particles, leading to the persistence or exacerbation of hydrophobicity (Zhou and Zhu 2005). For example, strongly sorbed non-ionic surfactants are known to have a strong retention capability for hydrophobic organic compounds, resulting in the reduced availability of hydrophobic substances for degradation and removal (Zhou and Zhu 2005). Therefore, it is possible that a non-ionic sulfate surfactant formed on the surfaces of samples $B / C-1$ and Bm-1, altering the WR of the affected materials. 


\section{Implications for Reclamation}

As mentioned, the WR-depth relationship that was observed in the majority of the AOSM is consistent with onion-skin weathering. This has important implications for the salvaging of soil cover materials as well as their re-placement. Because AOSM from deep soils is at a low stage of weathering and thus has the potential for a high level of WR, discreet salvage or salvage by depth, such as the $\mathrm{Bm}$ and $\mathrm{B} / \mathrm{C}$ horizons salvages, will create a natural separation of materials into two classes: ASOM from the Bm (shallow) is predominantly wettable or subcritically water repellent, while the $B / C$ salvage (deep) contains a much greater proportion of water repellent AOSM. For the former, AOSM may still absorb and store water even when experiencing excessive drought, but on the whole the latter may not. Therefore, depending on the site specific conditions, separate placement may be advantageous (i.e., when soils are excessively dry). In such a case, AOSM from the Bm salvage could be placed in the near surface (i.e., rooting zone) and AOSM from the B/C salvage placed deeper in the profile (i.e., below rooting zone). This arrangement will promote hydrophilic conditions by preventing the relatively water repellent AOSM of the deeper salvage from undergoing excessive drying and; therefore, alleviating the potential for the AOSM to become highly water repellent. The presence of excessively dry, highly water repellent oil sand material in the near surface or on the soil surface could limit the infiltration of water into the soil profile and; consequently, reduce soil water storage. This may be particularly relevant when considering the construction of a sloping landscape, where water repellent AOSM placed in the near surface has the potential to reduce infiltration and promote the occurrences of overland flow and erosion.

WR increases with depth into the AOSM. This suggests that it may be beneficial to conduct soil salvaging, stockpiling, and placement in a manner which minimizes or avoids excessively breaking up the AOSM, so that the relatively water repellent inner portions of the material are not overly exposed. The more hydrophilic outer portions will likely absorb a greater amount of water than the highly water repellent inner portions and; therefore, when AOSM are in-tact their 
outer portions will more often contain water, which may make it easier for the highly water repellent inner portions to also absorb and store water. Handling of the AOSM during cold weather (i.e., winter) would minimize its breakup because under low temperatures the oil in the AOSM is extremely viscous, making these materials relatively rigid.

Several CA measurements were also made by Rosso (2016) on soil matrix from a sand textured B/C horizons salvage collected from the ASCS area. The results showed maximum CAs ranging between $11^{\circ}$ and $45^{\circ}$, classifying the soil as subcritically water repellent. Crosscomparison between AOSM from our study and soil matrix from Russo (2016), as well as Hunter et al. (2011), suggests that AOSM is more water repellent than the surrounding soil matrix. This could result in a slower drainage of water through AOSM deposits. Given the current information, it is difficult to predict whether the incorporation of the more water repellent AOSM in reclamation soils will have a positive or negative effect on improving soil water storage. More information, such as the water infiltrability of AOSM in reclamation soils, in addition to the maximum potential water repellency obtained from this study, is needed in order to answer this question.

\section{CONCLUSIONS}

It seems likely that AOSM weathers in an onion-skin manner, in terms of both salvage depth and depth into individual AOSM samples: there is a greater degree of weathering and lower TOC and WR in the shallow salvage materials, and similarly a greater degree of weathering and lower TOC and WR on the surface of individual AOSM than at depth.

It is apparent that AOSM show a range of water repellent behavior in terms of both degree and persistence. Regardless, the subcritical nature of the WR in AOSM suggests that water absorption will still occur, albeit relatively slowly. The majority of the samples allowed infiltration to commence within one minute of exposure, indicating that repellency will likely persist only during periods of extensive drought, and only in the small portion of materials that show a severe or extreme persistence of WR. However, this small amount of hydrophobic material has 
the potential to significantly impact the hydrology of an affected area. The results from previous studies appear to support this, which show that sandy soil matrix from the study area has a considerably lower degree of WR and absorbs water more effectively than the AOSM from our current study. Nonetheless, the ability of the AOSM to allow at least some infiltration will minimize the negative effects of WR-related phenomena.

\section{ACKNOWLEDGEMENTS}

We gratefully acknowledge Canada's Oil Sands Innovation Alliance (COSIA) and the University of Saskatchewan for financial support. We thank Syncrude Canada Ltd. for providing access to research sites and logistical support throughout this study. A special thank you is extended to Dr. Derek Peak from the University of Saskatchewan, for his invaluable technical assistance and access to infrared spectroscopy equipment. The authors also extend their gratitude to Marty Yarmuch from Syncrude Canada Ltd. as well as Trent Pernitsky, Mark Sigouin, Carolyn Murray, Anqi Chen, and Henry Chau from the University of Saskatchewan for their assistance in the field and laboratory.

\section{REFERENCES}

Adams, R.H., Cerecedo-Lopez, R.A., Alejandro-Alvarez, L.A., Dominguez-Rodriguez, V.I., and Nieber, J.L. 2016. Treatment of water-repellent petroleum-contaminated soil from Bemidji, Minnesota, by alkaline desorption. Int. J. Environ. Sci. Technol. 13: 2249-2260. doi:10.1007/s13762-016-1058-4.

Bachmann, J., Deurer, M., and Arye, G. 2007. Modeling water movement in heterogeneous water-repellent soil: 1. Development of a contact angle-dependent water-retention model. Vadose Zone J. 6: 436-445. doi: 10.2136/vzj2006.0060.

Bauters, T.W.J., Steenhuis, T.S., Dicarlo, D.A., Nieber, J.L., Dekker, L.W., Ritsema, C.J., Parlange, J.-Y., and Haverkamp, R. 2000. Physics of water repellent soils. J. Hydrol. 231232: 233-243. doi:10.1016/S0022-1694(00)00197-9. 
Beckingham, J.D., and Archibald, J.H. 1996. Field guide to ecosites of northern Alberta. Natural Resources Canada, Canadian Forest Service, Northern Forestry Centre, Edmonton, Alberta. Special Report 5.

Behrens, R., Bouchez, J., Schuessler, J.A., Dultz, S., Hewawasam, T., and von Blanckenburg, F. 2015. Mineralogical transformations set slow weathering rates in low-porosity metamorphic bedrock on mountain slopes in a tropical climate. Chem. Geol. 411: 283-298. doi:10.1016/j.chemgeo.2015.07.008.

Bisdom, E.B.A., Dekker, L.W., and Schoute, J.F.T. 1993. Water repellency of sieve fractions from sandy soils and relationships with organic material and soil structure. Geoderma 56: 105-118. doi:10.1016/0016-7061(93)90103-R.

Brassington, K.J., Hough, R.L., Paton, G.I., Semple, K.T., Risdon, G.C., Crossley, J., Hay, I., Askari, K., and Pollard, S.J.T. 2007. Weathered hydrocarbon wastes: A risk management primer. Crit. Rev. Environ. Sci. Technol. 37: 199-232. doi:10.1080/10643380600819625.

Brunner, C., Wolf, M., and Bachofen, R. 1987. Enrichment of bitumen-degrading microorganisms. FEMS Microbiol. Lett. 43: 337-344.

Buczko, U., Bens, O., and Durner, W. 2006. Spatial and temporal variability of water repellency in a sandy soil contaminated with tar oil and heavy metals. J. Contam. Hydrol. 88: 249268. doi:10.1016/j.jconhyd.2006.07.002.

Canadian Council of Ministers of the Environment (CCME) 2008. Canada-wide standards for petroleum hydrocarbons $(\mathrm{PHC})$ in soil. [Online] Available: http://www.ccme.ca/files/Resources/csm/phc_cws/\%0Aphc_standard_1.0_e.pdf (accessed 17.02.21).

Cerniglia, C.E. 1992. Biodegradation of polycyclic aromatic hydrocarbons. Biodegradation 3: 351-368. doi:10.1007/BF00129093.

Chau, H.W., Biswas, A., Vujanovic, V., and Si, B.C. 2014. Relationship between the severity, persistence of soil water repellency and the critical soil water content in water repellent 
soils. Geoderma 221-222: 113-120. doi:10.1016/j.geoderma.2013.12.025.

Cumulative Environmental Management Association (CEMA) 2006. Land capability classification system for forest ecosystems in the oil sands, 3rd edition. Volume 1: Field manual for land capability determination. [Online] Available: http://cemaonline.ca/index.php/administration/doc_download/90-land-capabilityclassification-system-for-forest-ecosystems-manual-Iccs (accessed 17.02.21).

Dane, J.H., and Topp, G.C. (eds.) 2002. Methods of soil analysis: Part 4 - Physical methods. SSSA Book Series 5, Madison, WI.

Dekker, L.W., and Ritsema, C.J. 1994. How water moves in a water repellent soil 1. Potential and actual water repellency. Water Resour. Res. 30: 2507-2517.

Diehl, D. 2013. Soil water repellency: Dynamics of heterogeneous surfaces. Colloids Surfaces A Physicochem. Eng. Asp. 432: 8-18. doi:10.1016/j.colsurfa.2013.05.011.

Doerr, S.H., Shakesby, R.A., and Walsh, R.P.D. 2000. Soil water repellency: Its causes, characteristics and hydro-geomorphological significance. Earth Sci. Rev. 51: 33-65. doi:10.1016/S0012-8252(00)00011-8.

Eastcott, L., Shiu, W.Y., and Mackay, D. 1988. Environmentally relevant physical-chemical properties of hydrocarbons: A review of data and development of simple correlations. Oil Chem. Pollut. 4: 191-216. doi:10.1016/S0269-8579(88)80020-0.

Fleming, M. 2012. Petroleum hydrocarbon content, leaching and degradation from surficial bitumens in the Athabasca oil sands region. M.Sc. thesis, University of Saskatchewan. Frontera-Suau, R. 2000. Impact of microbial community structure on crude oil biodegradation. Ph.D. Dissertation, Medical University of South Carolina. doi:10.16953/deusbed.74839. Government of Alberta (GOA) 2016. Introduction to oil sands. [Online] Available: http://www.capp.ca/publications-and-statistics/publications/287586 (accessed 17.02.21). Gu, Y. 2006. Oil sands weathering. M.Sc. thesis, University of Alberta. Hamlett, C.A.E., Shirtcliffe, N.J., McHale, G., Ahn, S., Bryant, R., Doerr, S.H., and Newton, M.I. 
2011. Effect of particle size on droplet infiltration into hydrophobic porous media as a model of water repellent soil. Environ. Sci. Technol. 45: 9666-9670.

Hein, F.J. 2006. Heavy oil and oil (tar) sands in North America: An overview \& summary of contributions. Nat. Resour. Res. 15(2): 67-84. doi:10.1007/s11053-006-9016-3.

Hirata, Y., Chigira, M., and Chen, Y. 2016. Spheroidal weathering of granite porphyry with welldeveloped columnar joints by oxidation, iron precipitation, and rindlet exfoliation. Earth Surf. Process. Landforms. doi:10.1002/esp.4008.

Huang, M., Barbour, S.L., Elshorbagy, A., Zettl, J.D., and Si, B.C. 2011. Water availability and forest growth in coarse-textured soils. Can. J. Soil Sci. 91: 199-210. doi:10.4141/cjss 10012 .

Hunter, A. 2011. Investigation of water repellency and critical water content in undisturbed and reclaimed soils from the Athabasca oil sands region of Alberta, Canada. M.Sc. thesis, University of Saskatchewan. [Online] Available:http://library2.usask.ca/theses/available/etd07072011-112233/unrestricted/HunterMSCThesis.pdf.

Jafvert, C.T., and Heath, J.K. 1991. Sediment- and saturated-soil-associated reactions involving an anionic surfactant (dodecylsulfate). 1. Precipitation and micelle formation. Environ. Sci. Technol. 25: 1031-1038. doi:10.1021/es00018a003.

Johnson, E.A., and Miyanishi, K. 2008. Creating new landscapes and ecosystems: The Alberta oil sands. Ann. N. Y. Acad. Sci. 1134: 120-145. doi:10.1196/annals.1439.007.

Leskiw, L.A., Arregoces, C., Boorman, S., Zakele, T., and Startsev, A. 2006. Hydrocarbons in natural oil sands soils: Field survey. Report prepared for the Cumulative Environmental Management Association (CEMA) by Paragon Soil and Environmental Consulting Inc. [Online] Available:http://library.cemaonline.ca/ckan/dataset/2006-0031/resource/651a3c3280e7-462d-94d9-839a361598cf (accessed 17.02.21).

Meyer, R.F., Attanasi, E.D., and Freeman, P.A. 2007. Heavy oil and natural bitumen resources in geological basins of the world. U.S. Geological Survey Open-File Report 2007-1084. 
[Online] Available: https://pubs.usgs.gov/of/2007/1084/OF2007-1084v1.pdf (accessed 17.02.21).

Mossop, G.D. 1980. Geology of the Athabasca oil sands. Science 207: 145-152.

Müller, K., and Deurer, M. 2011. Review of the remediation strategies for soil water repellency. Agric. Ecosyst. Environ. 144: 208-221. doi:10.1016/j.agee.2011.08.008.

Natural Regions Committee 2006. Natural regions and subregions of Alberta. Compiled by D.J. Downing and W.W. Pettapiece. Government of Alberta. Pub. No. T/852. [Online] Available: http://www.albertaparks.ca/media/2942026/nrsrcomplete_may_06.pdf (accessed 17.02.21)

Neil, E.J., and Si, B.C. (n.d.). Interstitial hydrocarbons reduce the infiltration rates of coarsetextured reclamation materials from the Athabasca oil sands. Submitted to Catena. [In Review].

Oil Sands Vegetation Reclamation Committee 1998. Guidlines for reclamation to forest vegetation in the Athabasca oil sands region. [Online] Available: https://extranet.gov.ab.ca/env/infocentre/info/library/6869.pdf (accessed 17.02.21).

Page, C.A., Bonner, J.S., Sumner, P.L., and Autenrieth, R.L. 2000. Solubility of petroleum hydrocarbons in oil/water systems. Mar. Chem. 70: 79-87. doi:10.1016/S03044203(00)00016-5.

Peak, D., Ford, R.G., and Sparks, D.L. 1999. An in situ ATR-FTIR investigation of sulfate bonding mechanisms on goethite. J. Colloid Interface Sci. 218: 289-299. doi:10.1006/jcis.1999.6405.

Quyum, A., Achari, G., and Goodman, R.H. 2002. Effect of wetting and drying and dilution on moisture migration through oil contaminated hydrophobic soils. Sci. Total Environ. 296: 7787. doi:10.1016/S0048-9697(02)00046-3.

Rasband, W. (1997-2012). ImageJ, U.S. National Institutes of Health, Bethesda, Maryland, USA. [Online] Available: http://rsbweb.nih.gov/ij/docs/guide/user-guide.pdf (accessed 
17.02.21).

Reid, B.J., Jones, K.C., and Semple, K.T. 2000. Bioavailability of persistent organic pollutants in soils and sediments-a perspective on mechanisms, consequences and assessment. Environ. Pollut. 108: 103-112. doi:10.1016/S0269-7491(99)00206-7.

Rosso, M.E.M. 2016. Observations of soil moisture dynamics associated with hydrocarbon affected and layered coarse textured soils. M.Sc. thesis, University of Saskatchewan.

Roy, J.L., and McGill, W.B. 2000. Investigation into mechanisms leading to the development, spread and persistence of soil water repellency following contamination by crude oil. Can. J. Soil Sci. 80(4): 595-606. doi:10.4141/S99-091.

Roy, J.L., Mcgill, W.B., Lowen, H.A., and Johnson, R.L. 2003. Relationship between water repellency and native and petroleum-derived organic carbon in soils. J. Environ. Qual. 32: $583-590$.

Shirtcliffe, N.J., McHale, G., Atherton, S., Newton, M.I. 2010. An introduction to superhydrophobicity. Advances in Colloid and Interface Science. 161: 124-138.

Soil Classification Working Group 1998. The Canadian system of soil classification, 3rd edition. Agric. Agri-Food Canada Publ. 1646 (Revised). [Online] Available: http//sis.agr.gc.ca/cansis/publications/manuals/1998-cssc-ed3/cssc3_manual.pdf (accessed 17.02.21).

Stalder, A.F., Melchior, T., Müller, M., Sage, D., Blu, T., and Unser, M. 2010. Low-bond axisymmetric drop shape analysis for surface tension and contact angle measurements of sessile drops. Colloids Surfaces A Physicochem. Eng. Asp. 364: 72-81. doi:10.1016/j.colsurfa.2010.04.040.

Takamura, K. 1982. Microscopic structure of Athabasca oil sand. Can. J. Chem. Eng. 60: 538545. doi:10.1002/cjce.5450600416.

Visser, S. 2008. Petroleum hydrocarbons (PHCs) in tar balls: degradation potential, leaching potential and toxicity to ecological receptors. Report prepared for the Cumulative 
Environmental Management Association (CEMA). [Online] Available:

http://library.cemaonline.ca/ckan/dataset/2006-0022/resource/02ebd1b3-8d4a-48ce-b5e288ed8fae41f6 (accessed 17.02.21).

Walker, J.D., Colwell, R.R., and Petrakis, L. 1976. Biodegradation rates of components of petroleum. Can. J. Microbiol. 22: 1209-1213. doi:10.1139/m76-179.

Wang, D.L., and Anderson, D.W. 1998. Direct measurement of organic carbon content in soils by the Leco CR-12 carbon analyzer. Commun. Soil Sci. Plant Anal. 29: 15-21. doi:10.1080/00103629809369925.

Zettl, J.D., Barbour, S.L., Huang, M., Si, B.C., and Leskiw, L.A. 2011. Influence of textural layering on field capacity of coarse soils. Can. J. Soil Sci. 91: 133-147. doi:10.4141/cjss09117.

Zhao, Y., and Machel, H.G. 2011. Biodegradation characteristics of bitumen from the Upper Devonian Grosmont reservoir, Alberta, Canada. Bull. Can. Pet. Geol. 59: 112-130. doi:10.2113/gscpgbull.59.2.112.

Zhou, W., and Zhu, L. 2005. Solubilization of polycyclic aromatic hydrocarbons by anionicnonionic mixed surfactant. Colloids Surfaces A Physicochem. Eng. Asp. 255: 145-152. doi:10.1016/j.colsurfa.2004.12.039. 


\section{Figure captions}

Figure 1. Aggregated oil sand material (AOSM) from three stages of weathering (low, medium, and high), placed on top of their surrounding sandy subsoil. Measurement scale in centimeters.

Figure 2. Weathering classification (low, med, high) of AOSM from three soil salvage types: Bm (15-50 cm), B/C (50-100 cm), and SS $(15-200 \mathrm{~cm})$.

Figure 3. Total mass-based carbon content at various depths into individual AOSMs for all samples (left) and samples from various weathering classes (low; medium and high combined) (right).

Figure 4. Mean degree of water repellency of AOSM, grouped by soil salvage type (left) and extent of weathering (right).

Figure 5. Time for the AOSM water contact angles to become $\leq 90^{\circ}$, grouped by soil salvage type (left) and extent of weathering (right).

Figure 6. Mean persistence of water repellency of AOSM, grouped by soil salvage type (left) and extent of weathering (right).

Figure 7. WDPT at various depths into four AOSM samples, grouped by soil salvage type (left) and extent of weathering (right). 
Table 1. Weathering stage determination for aggregated oil sand material.

\begin{tabular}{llll}
\hline $\begin{array}{c}\text { Weathering } \\
\text { stage }\end{array}$ & Colour $^{\text {a }}$ & $\begin{array}{c}\text { Petroleum } \\
\text { odour }\end{array}$ & $\begin{array}{c}\text { Physical fragmentation } \\
\text { requirements }\end{array}$ \\
\hline Low & black & Strong & hammer and chisel \\
Medium & dark grey & Mild & by hand \\
High & light grey & None & soft-bristled paint brush \\
\hline
\end{tabular}

aLight coloured surface precipitate indicates a greater stage of weathering. 


\section{Table 2.}

Mean \pm standard deviation of total organic carbon content ( $\%$ by mass) of soil matrix, outer AOSM, and inner AOSM from three soil salvage types

\begin{tabular}{cccccc}
\hline \multirow{2}{*}{$\begin{array}{c}\text { Salvage } \\
\text { type }\end{array}$} & \multirow{2}{*}{$\begin{array}{c}\text { Depth } \\
(\mathrm{cm})\end{array}$} & $\begin{array}{c}\text { AOSM }^{\mathrm{a}} \\
\text { weathering }\end{array}$ & \multicolumn{2}{c}{ Soil } & \multicolumn{2}{c}{ AOSM $^{\mathrm{a}}$} \\
\cline { 4 - 6 } & & & matrix & Outer & Inner \\
\hline Bm & $15-50$ & Med-High & $0.6 \pm 0.09$ & $6.3 \pm 2.1$ & $7.9 \pm 2.1$ \\
B/C & $50-100$ & Low-Med & $0.4 \pm 0.03$ & $9.7 \pm 5.4$ & $11.2 \pm 3.1$ \\
SS & $15-200$ & Med-High & $0.7 \pm 0.06$ & $6.5 \pm 2.0$ & $6.6 \pm 1.0$ \\
\hline
\end{tabular}

${ }^{\mathrm{a}} \mathrm{AOSM}$ = aggregated oil sand material 


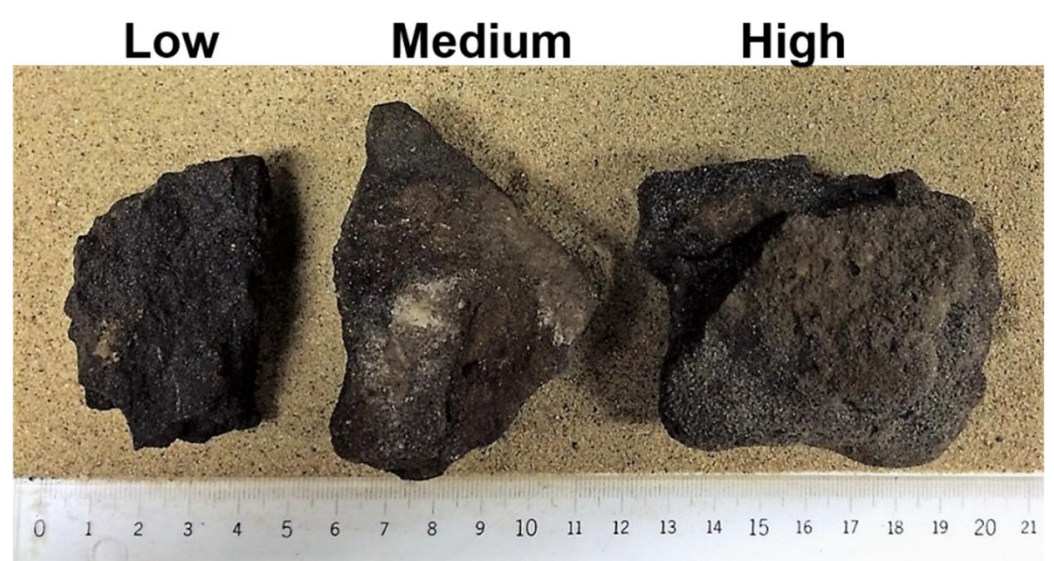

https://mc.manuscriptcentral.com/cjss-pubs 


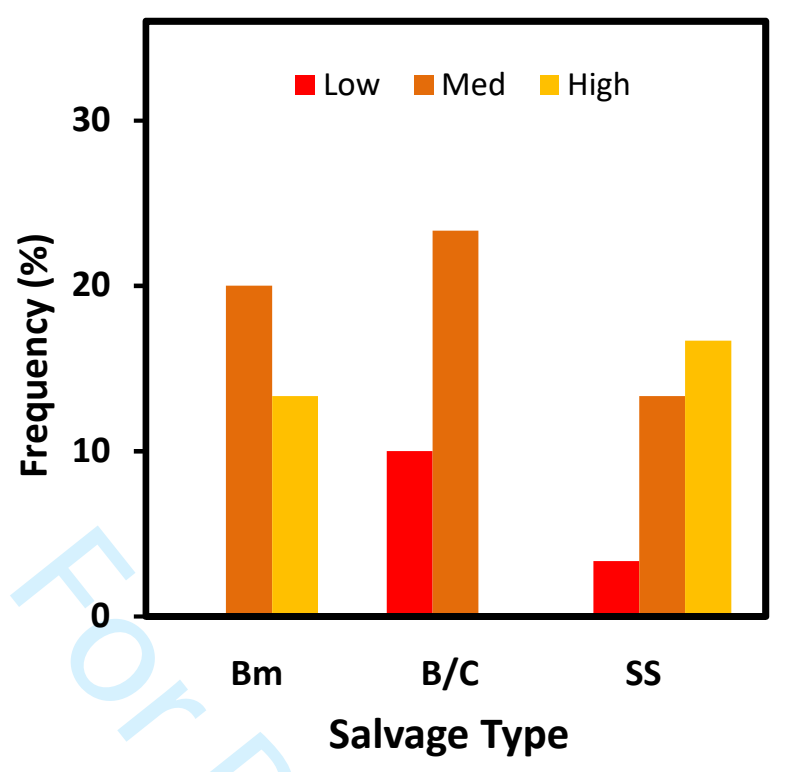

https://mc.manuscriptcentral.com/cjss-pubs 

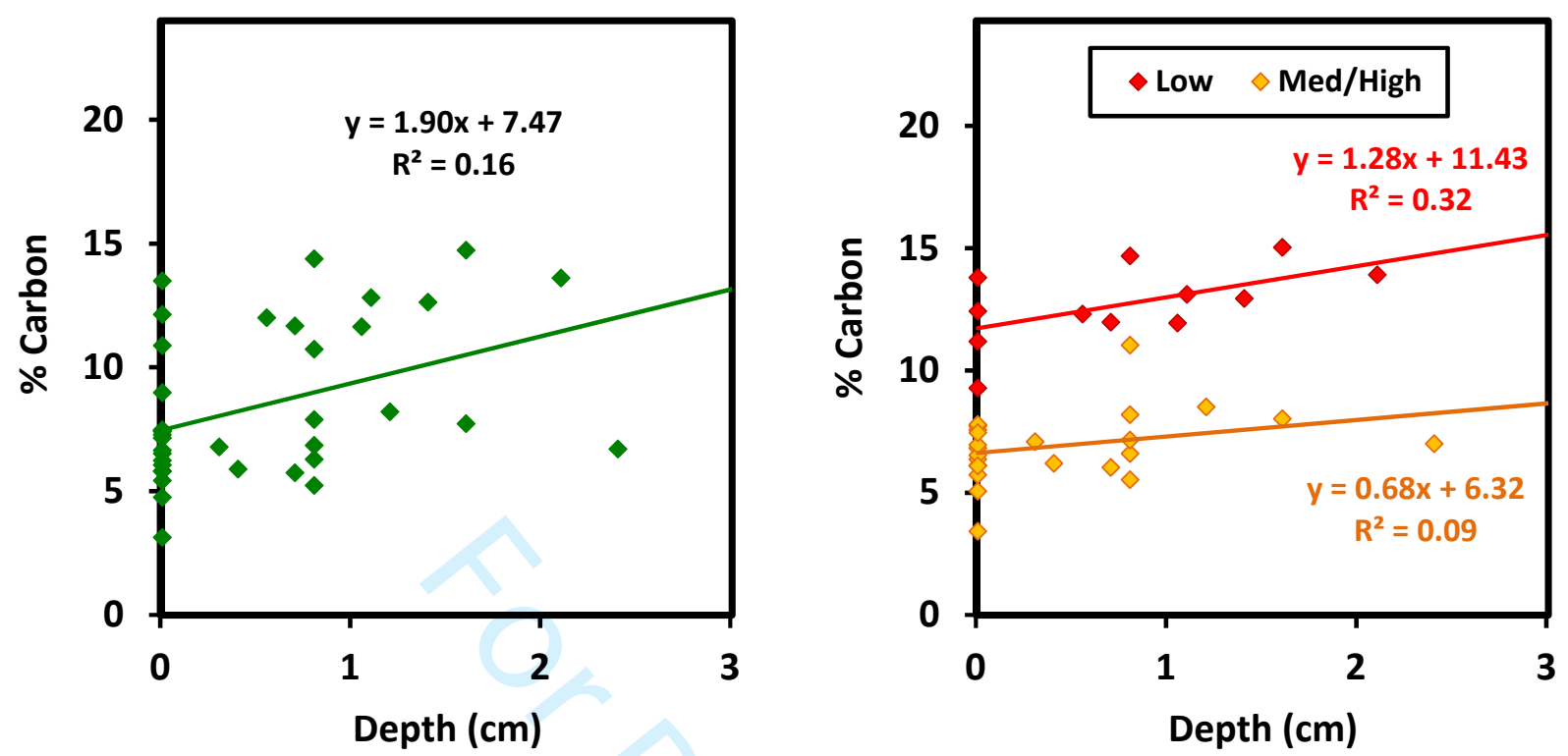

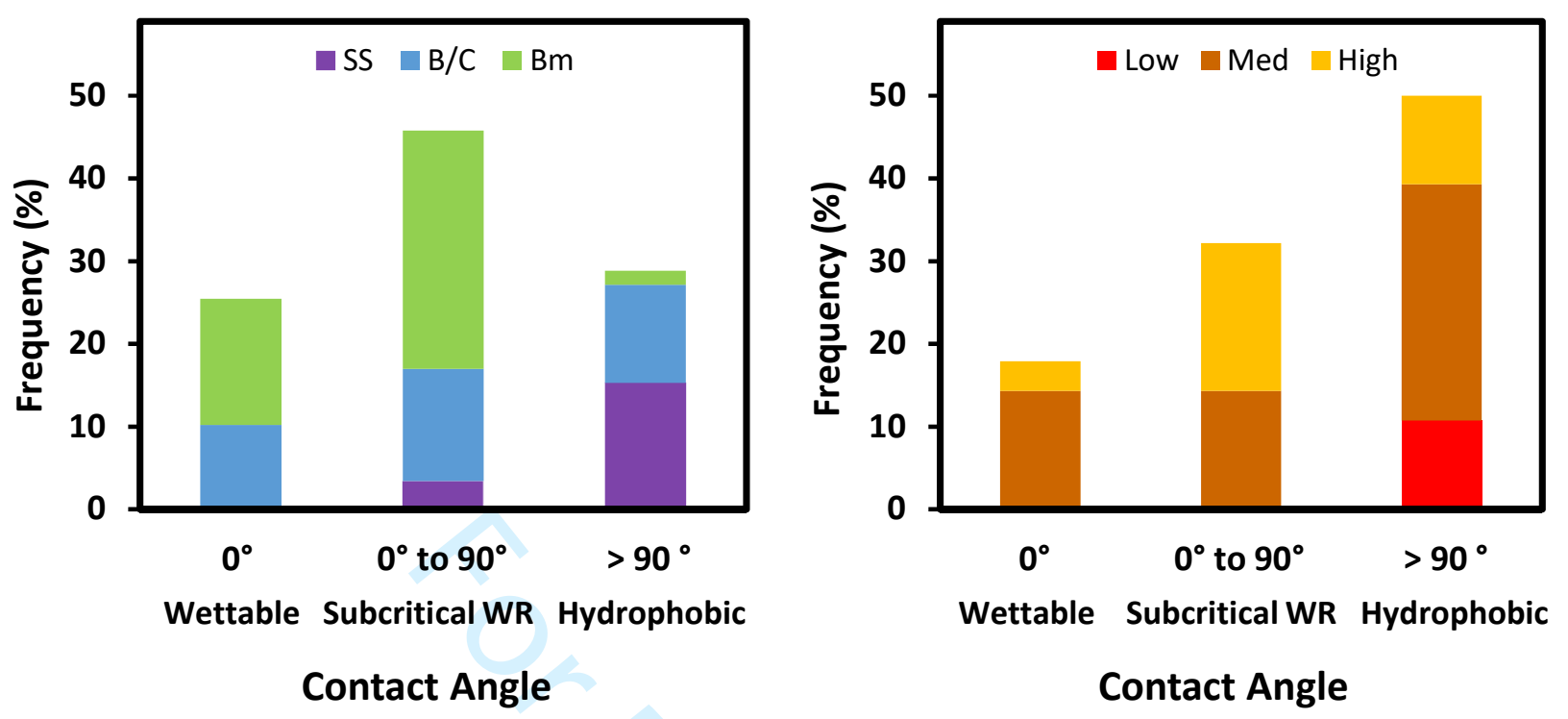

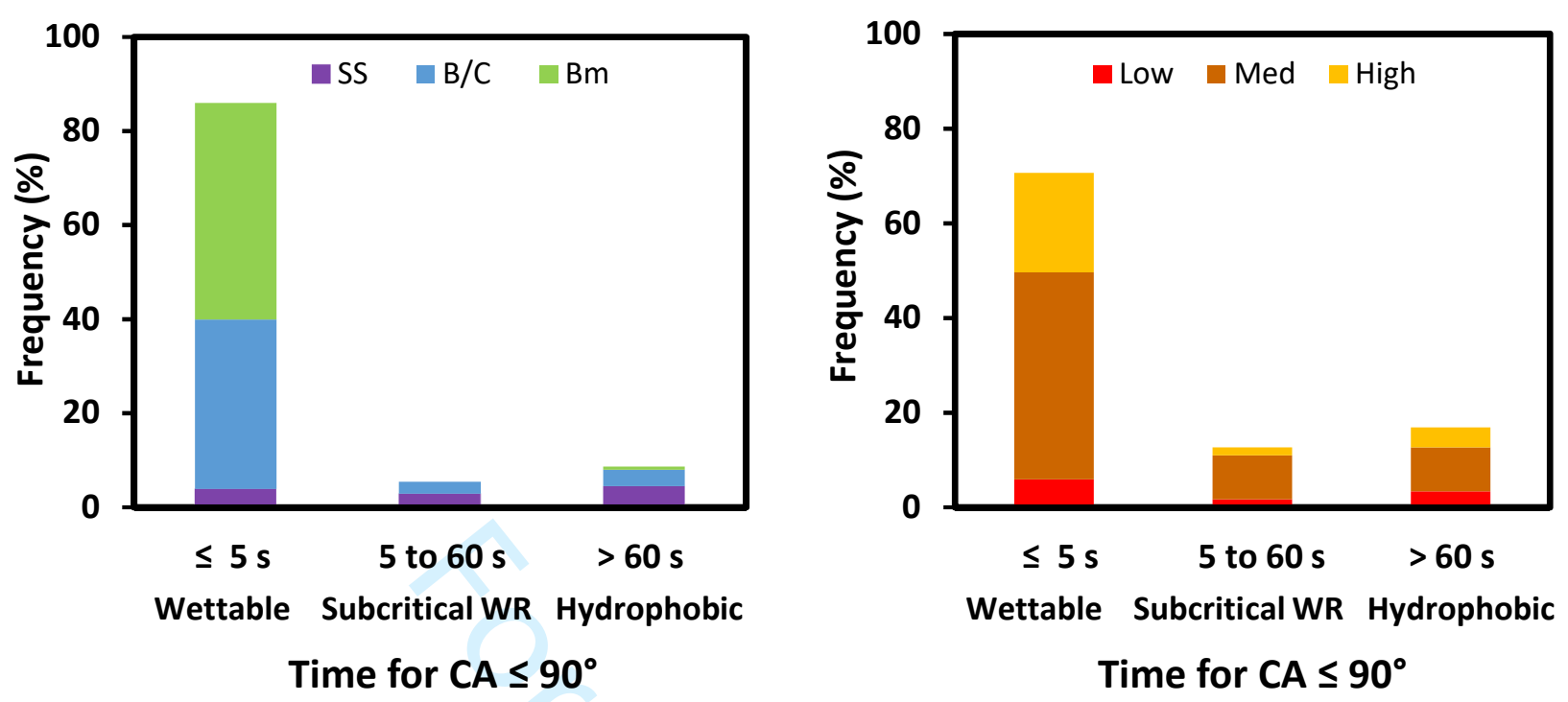

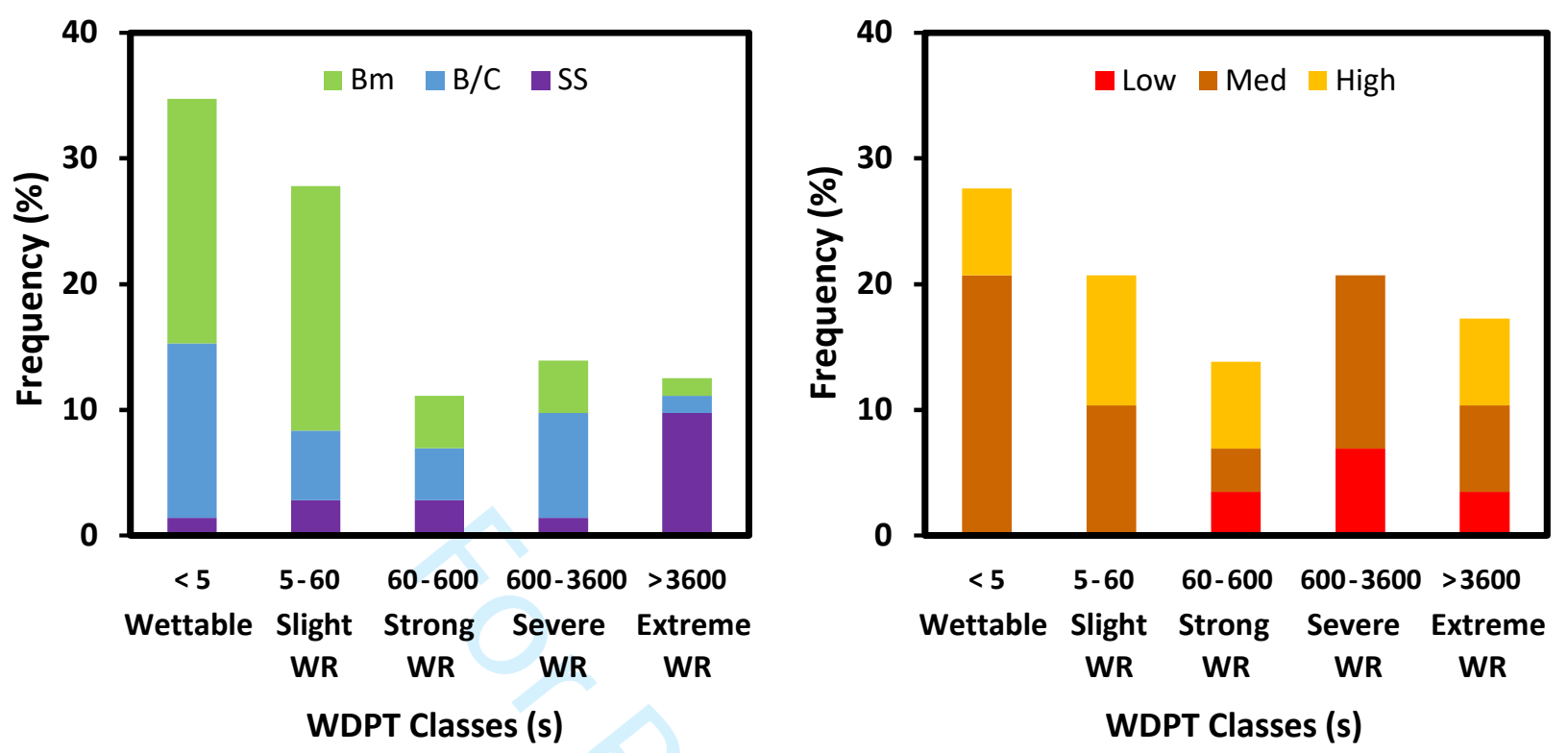

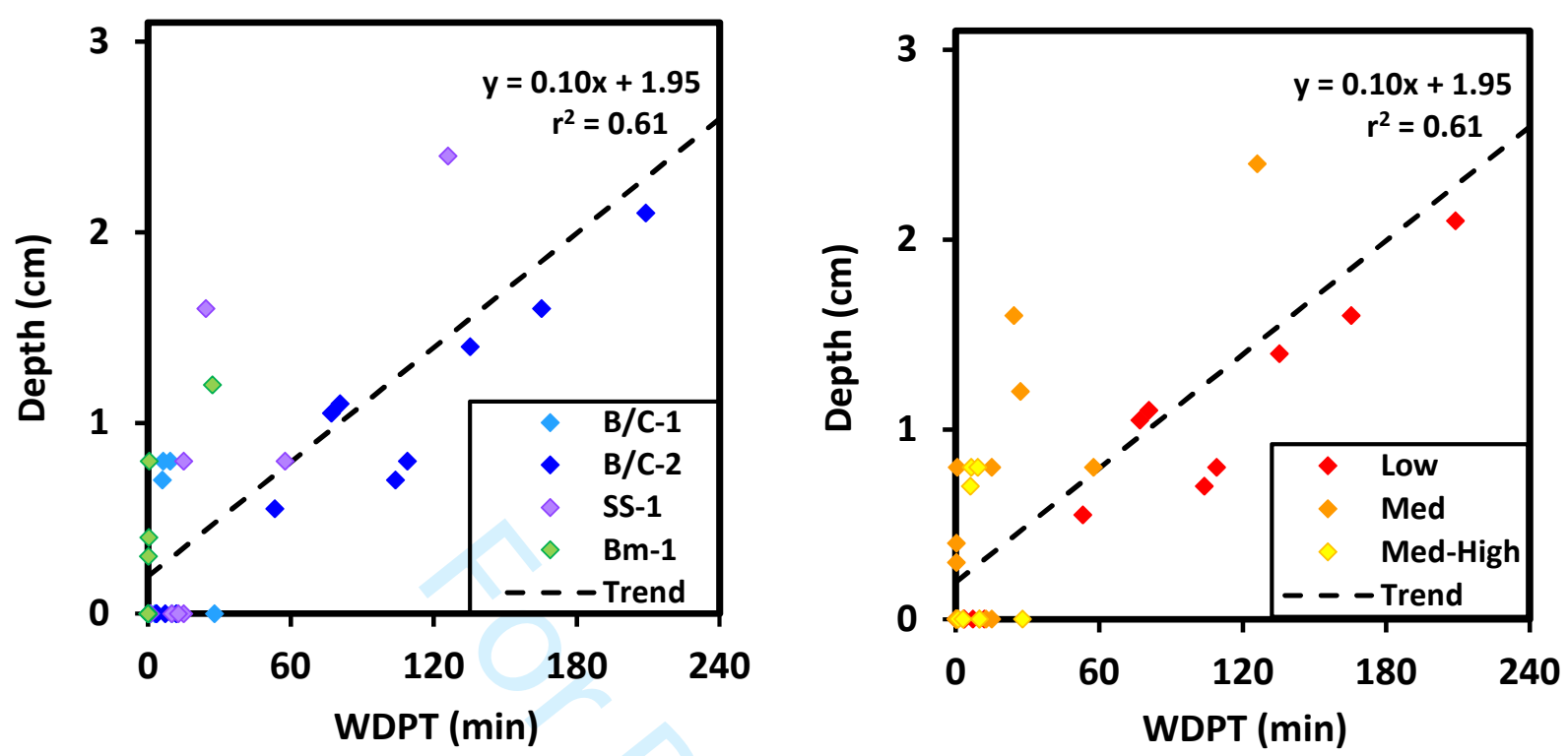